\title{
Lack of cerebellar tDCS effects on learning of a complex whole body dynamic balance task in middle-aged (50-65 years) adults
}

\author{
M. Rauscher ${ }^{1}$, F. Yavari ${ }^{2}$, G. Batsikadze ${ }^{1}$, N. Ludolph ${ }^{3}$, W. $\| g^{3}$, M. A. Nitsche ${ }^{2,4}$, D. Timmann ${ }^{1}$ and K. M. Steiner ${ }^{1 *}$ (1)
}

\begin{abstract}
Background: Cerebellar transcranial direct current stimulation (tDCS) is widely considered as a promising noninvasive tool to foster motor performance and learning in health and disease. The results of previous studies, however, are inconsistent. Our group failed to provide evidence for an effect of cerebellar tDCS on learning of a complex whole body dynamic balance task in young and healthy participants. Ceiling effects in the young study population are one possible explanation for the negative findings.
\end{abstract}

Methods: In the present study, we therefore tested 40 middle-aged healthy participants between the ages of 50 to 65 years. Participants received either anodal or sham cerebellar tDCS using a double-blinded study design while performing a balance task on a Lafayette Instrument 16,030 stability platform ${ }^{\oplus}$. Mean platform angle and mean balance time were assessed as outcome measures.

Results: Significant learning effects were found in all participants. Balancing performance and learning rate was significantly less in the group of middle-aged adults compared to our previous group of young adults. No significant effects of cerebellar tDCS were observed.

Conclusions: Our findings are in line with other studies that have failed to prove robust effects of cerebellar tDCS on motor learning. The present findings, however, do not exclude cerebellar tDCS effects. tDCS effects may be more prominent after repeated stimulation, using other stimulus parameters, in patient populations, or in other motor learning tasks.

Trial registration: Not applicable.

Keywords: Cerebellum, Transcranial direct current stimulation, Motor learning, Aging

\section{Background}

The cerebellum is essential for motor performance and motor learning [44]. Motor functions decline not only in cerebellar disease but also in physiological aging. An age-related reduction of cerebellar volume is well known and starts around the age of 40 years [29]. Balance and gait deteriorate with age $[22,23]$. Likewise, an agerelated decline of motor learning is well known $[1,5]$

\footnotetext{
* Correspondence: katharinamarie.steiner@uk-essen.de

'Department of Neurology, Essen University Hospital, University of

Duisburg-Essen, Hufelandstr. 55, 45147 Essen, Germany

Full list of author information is available at the end of the article
}

and age-related reduction of cerebellar function is one likely factor. For example, older adults exhibited lower activation in cerebellar lobule VI than young adults in a motor sequence learning task [5]. Transcranial direct current stimulation (tDCS) has received increasing attention over the last two decades as a non-invasive technique to modulate neuroplasticity. More recently, the cerebellum has been identified as a possible target of tDCS $[28,33]$. Several studies have shown that cerebellar tDCS modulates cerebellar brain inhibition (CBI) $[2,13]$ a physiological measure which quantifies the inhibitory projection from the cerebellar cortex to the motor

(c) The Author(s). 2020 Open Access This article is licensed under a Creative Commons Attribution 4.0 International License, which permits use, sharing, adaptation, distribution and reproduction in any medium or format, as long as you give appropriate credit to the original author(s) and the source, provide a link to the Creative Commons licence, and indicate if changes were made. The images or other third party material in this article are included in the article's Creative Commons licence, unless indicated otherwise in a credit line to the material. If material is not included in the article's Creative Commons licence and your intended use is not permitted by statutory regulation or exceeds the permitted use, you will need to obtain permission directly from the copyright holder. To view a copy of this licence, visit http://creativecommons.org/licenses/by/4.0/. 
cortex via the dentato-thalamo-cortical pathway [42]. Cerebellar tDCS has also been shown to modify fMRI activity of the cerebellar cortex [24] and cerebellar nuclei [20]. With respect to age-related deterioration and furthermore, in cerebellar disease, tDCS may have beneficial effects [3, 4]. For example, adaptive postural control has been shown to be improved by anodal cerebellar tDCS in healthy volunteers [27]. Anodal cerebellar tDCS has been shown to improve locomotor adaptation in a split-belt paradigm (2011). Furthermore, Cantarero et al. [7] demonstrated faster acquisition of a sequential visual isometric pinch task with anodal cerebellar tDCS. Hardwick and Celnik [16] reported that cerebellar tDCS was able to compensate for age-related decline in a reach adaptation task. Cerebellar tDCS, however, did not improve acquisition of a complex whole body dynamic balance task [36]. Young and healthy participants were tested who possibly performed already at maximum possible learning rate preventing the observation of tDCS effects. Therefore, we re-examined possible cerebellar tDCS effects in the same dynamic balance task in middle-aged and healthy adults.

\section{Methods}

\section{Participants}

Forty healthy participants (20 male, 20 female) aged 5065 years took part in this study. Participants were pseudorandomly assigned to two groups - a verum stimulation group and a sham stimulation group. Male and female participants were equally distributed across groups. None of the participants suffered from any neurological, psychiatric or orthopedic disorders or were taking centrally acting medication. All participants were non-smokers, except one. All participants were examined by an experienced neurologist (MR) on the day of the experiment. Clinical assessment included the
International Cooperative Ataxia Rating Scale [ICARS [41]] and the Scale for the Assessment and Rating of Ataxia [SARA [34]]. The neurological examination was unremarkable in all participants. In a previous study of our group [37], male participants performed worse than female correlating with body height. Because foot position was fixed, biomechanical constraints likely explain the lower performance in taller participants. Therefore, participants taller than $190 \mathrm{~cm}$ were excluded from the present study. The study was approved by the local ethics committee (Medical Faculty of the University Duisburg-Essen) and conducted in accordance with the Declaration of Helsinki.

\section{Dynamic balance task}

The dynamic balance task is described in Steiner et al. [36] in more detail. The Lafayette Instrument 16,030 Stability Platform ${ }^{\circ}$ was used for balance training (Fig. 1) [19]. Participants stood on the platform and were instructed to hold it in a horizontal position as long as possible. The participants were strapped into a safety harness during training. They performed 20 trials lasting $30 \mathrm{~s}$ each. The platform was lowered to the ground towards alternating sides for $30 \mathrm{~s}$ between the trials in order to avoid muscle fatigue. The mean platform angle deviation was measured during each trial by an analogto-digital converter (National Instruments, Germany) at $1 \mathrm{kHz}$. Furthermore, the mean balance time, which is defined as the time during which the platform could be held between $-5^{\circ}$ and $+5^{\circ}$, was calculated.

\section{Cerebellar transcranial direct current stimulation}

Cerebellar tDCS was applied by a neuroConn DCstimulator at a current intensity of $2.8 \mathrm{~mA}$ to allow for the same current density $\left(0.08 \mathrm{~mA} / \mathrm{cm}^{2}\right)$ as in Celnik et al. [[16], see also [13, 14]]. An electrode of the size of

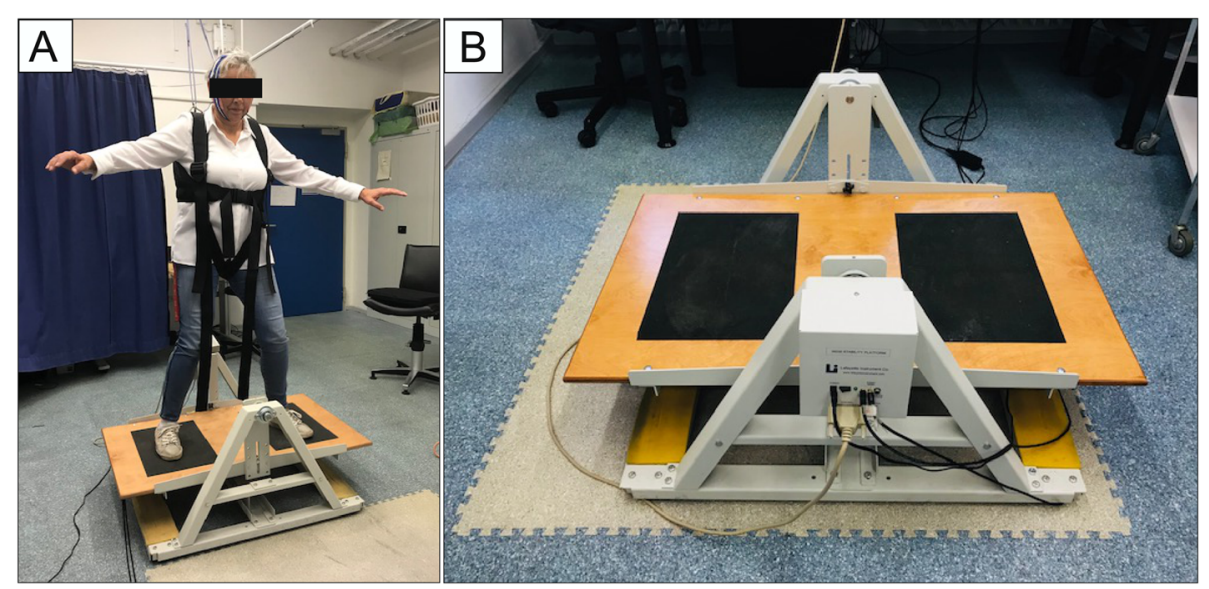

Fig. 1 Experimental set-up. a Middle-aged woman (57 years old) performing the complex whole body dynamic balance task. Informed written consent has been given for publishing the picture. b Lafayette Instrument 1600 stability platform ${ }^{\circledast}$ 
$5 \mathrm{~cm} \times 7 \mathrm{~cm}$ was placed above the cerebellum. The electrode was horizontally oriented. The upper edge of the electrode was located $0.5 \mathrm{~cm}$ above the inion (center 2 $\mathrm{cm}$ below the inion) [11]. Two return electrodes $(5 \mathrm{~cm} \times$ $5 \mathrm{~cm}$ ) were placed over each of the buccinator muscles [36]. The electrode positions were chosen with the aim of targeting both the vermis and the cerebellar hemispheres [36]. Ten20 conductive paste was used to affix the electrodes. In addition, cotton straps were wrapped around the head and the electrodes. tDCS was applied during training on the platform. The stimulator was switched on at the time the participant started the first trial (after the test trial) and stimulation lasted until the last trial. Thus, the duration of the stimulation was 19 min and thirty seconds ( 20 trials à $30 \mathrm{~s}$ and 19 breaks à $30 \mathrm{~s}$ between trials). tDCS was applied in a doubleblinded fashion, i.e. neither the examiner nor the participant knew whether verum or sham stimulation was applied. One group received anodal tDCS (stimulation group) whereas the other group received sham stimulation. In sham stimulation, the current was ramped up in $10 \mathrm{~s}$ and remained at $2.8 \mathrm{~mA}$ for a duration of $30 \mathrm{~s}$. tDCS started after the first trial. The first trial served as test trial to control for possible differences in performance between the two groups.

Modeling of tDCS electric field (EF) distribution was performed using SimNIBS, a freely available software package for simulating the effects of non-invasive brain stimulation (NIBS) techniques [40]. A realistic head model was created using T1- and T2-weighted average MRI templates in the age range of 55-59 years taken from the Neurodevelopmental MRI Database [[30] https://www.nitrc.org/projects/neurodevdata/]. Three electrodes covered with conductive gel were positioned over the same areas as in the experimental procedure (one $5 \mathrm{~cm} \times 7 \mathrm{~cm}$ electrode centered $2 \mathrm{~cm}$ below the inion, and two $5 \mathrm{~cm} \times 5 \mathrm{~cm}$ electrodes over the buccinator muscles). The current intensity was set to $2.8 \mathrm{~mA}$. The calculated normEF values were converted to nii using the msh2nii command and exported to Matlab (R2019a, version 9.6.0, The MathWorks Inc.). Then, using cerebellar masks extracted from the SUIT atlas [9] the average value of normEF strength was quantified in four cerebellar regions that are assumed to be involved in the task (i.e., i) vermis and anterior lobe, ii) Crus I, iii) Crus II and iv) lobule VIII, bilaterally).

\section{Statistical analysis}

An analysis of variance (ANOVA) with repeated measures was applied in order to test for group differences, with mean platform angle deviation and mean balance time as dependent variables, trials (1-20) as within subject factor and stimulation (verum vs. sham) as between subject factor. Results were considered significant at $p<$
0.05. Degrees of freedom were adjusted, if applicable, in accordance with Greenhouse and Geisser [15]. Statistical tests were performed using SPSS software (version 17, IBM Company, New York, USA). The Two One-Sided Test (TOST) procedure was applied to test for equivalence between the anodal and sham group [31, 35]. Equivalence was assumed when the 90\% confidence interval for the differences between the means of the anodal and sham groups fell within the range of $+/-1$ standard deviation of the respective mean of the sham group.

\section{Results}

\section{Modeling of tDCS electric field (EF) distribution}

Cerebellar stimulation effects as revealed by modelling of the electric field showed the highest values for Crus II bilaterally $[0.78 \mathrm{~V}$ per meter $(\mathrm{V} / \mathrm{m})]$ and lobule VIII bilaterally $(0.34 \mathrm{~V} / \mathrm{m})$, and lower values for Crus I bilaterally $(0.23 \mathrm{~V} / \mathrm{m})$ and the vermis/anterior lobe $(0.19 \mathrm{~V} /$ $\mathrm{m})$ (Table 1). Distribution of normEF values is shown in Fig. 2 overlayed on an average brain [age range 55-50 years, taken from the Neurodevelopmental MRI Database [30]; https://www.nitrc.org/projects/neurodevdata/].

\section{Dynamic balance task}

There was no significant difference regarding age or body height between the two stimulation groups [unpaired t-test: age: anodal group: mean $58.45 \pm 4.7$ years, sham group: mean $56 \pm 4.35$ years; $\mathrm{t}(38)=1.71, p=0.63$; body height: anodal group: mean $170.25 \pm 7.06 \mathrm{~cm}$, sham group: mean $169.3 \pm 7.43 \mathrm{~cm}$; t $(38)=0.42, p=0.93$ ]. There was no significant group difference in performance of the test trial without stimulation [mean platform angle: $\mathrm{t}(38)=0.05, p=0.42$; mean balance time: $\mathrm{t}(38)=$ $-0.66, p=0.37$; Fig. 3].

All participants improved over the course of the experiment (Fig. 4). Mean platform angle significantly decreased and mean balance time significantly increased across trials [trial effect: mean platform angle: $F(19$, $722)=27.4, p<0.001$; mean balance time: $\mathrm{F}(19,722)=$ $10.23, \mathrm{p}<0.001]$. There was no significant difference between the stimulation groups [stimulation effect: mean platform angle: $\mathrm{F}(1,38)=0.002, p=0.96$; mean balance time: $\mathrm{F}(1,38)=0.44, p=0.51]$ and no significant trial by stimulation interaction [mean platform angle: $\mathrm{F}(19$, $722)=1.53, p=0.68$, mean balance time: $\mathrm{F}(19,722)=$ $0.82, p=0.69$ ]. Including body height as a covariate in the ANOVA with repeated measures revealed similar results (group, trial, group by trial, height effects, all $p$ values $>0.1$.

The mean differences between the means over all trials in the anodal and the sham group were found to be equivalent $[\mathrm{t} \quad(32,48)=3.71, \quad p=0.0004 ;$ equivalence bounds: \pm 3.12 , alpha: 0.05$]$. 
Table 1 Mean values of the electric field (normEF) in four different regions of the cerebellum based on the SUIT atlas [9] calculated using SimNIBSC [32]

\begin{tabular}{lll}
\hline & Mean of normEF (V/m) & Labels of the included cerebellar regions from SUIT atlas \\
\hline Vermis plus the anterior lobe of cerebellum & 0.1782040 & $1-4,6,9,12,15,18,21,24,27$ \\
Crus I - both hemispheres & 0.2315656 & 10,8 \\
Crus II - both hemispheres & 0.7774634 & 13,11 \\
Lobule VIII - both hemispheres & 0.3386466 & $17,19,20,22$ \\
\hline
\end{tabular}

Numerically, male participants performed somewhat lower than female participants (Fig. 4). Therefore male and female participants were analyzed separately. Again, there were no significant differences between the anodal and sham groups [male participants only: mean platform angle: stimulation effect: $\mathrm{F}(1,18)=0.12, p=0.73$; mean balance time: stimulation effect: $\mathrm{F}(1,18)=0.04, p=0.84$; female participants only: mean platform angle: stimulation effect: $F(1,18)=0.13, p=0.73$; mean balance time: stimulation effect: $\mathrm{F}(1,18)=0.34, p=0.57]$. Trial by stimulation interactions were not significant, with trendwise effects regarding the mean platform angle in male participants [male participants only: mean platform angle: trial by stimulation interaction: $\mathrm{F}(19,342)=1.61$, $p=0.051$; mean balance time: trial by stimulation interaction: $F(19,342)=0.73, p=0.79$; female participants only: mean platform angle: trial by stimulation interaction: $F(19,342)=0.84, p=0.66$; mean balance time: trial by stimulation interaction: $\mathrm{F}(19,342)=0.82, p=$ 0.68] (Fig. 5a, b). Trial effects were significant (all $p$ values $<0.001$ ). Male participants were significantly taller than female participants [male participants: mean: $175.1 \pm 5.2 \mathrm{~cm}$, female participants: mean: $164.5 \pm 4.5 \mathrm{~cm}$; $\mathrm{t}(38)=6.89, p<0.001]$. There was however no significant correlation between body height and task performance (mean platform angle, mean of all trials, Pearson's correlation with body height: $\mathrm{r}=0.09, p=0.58$; mean balance time, mean of all trials, Pearson's correlation with body height: $\mathrm{r}=-0.12, p=0.48$ ).

Finally, we compared the group of all participants included in the present study to with the young healthy participants of our previous experiment [36]. Note that the experimental set-up, training paradigm and stimulation protocol was identical in the present study and the previous study, with the only exception of trial number, which was 15 trials in the previous study compared to 20 trials in the present study. The older adults performed significantly worse than the young healthy adults [mean platform angle (mean of the first 15 trials): young adults: $6.43 \pm 1.57$ degrees, older adults: $10.1 \pm 2.61$ degrees; group effect: $\mathrm{F}(1,68)=45.5, p<0.001$; mean balance time (mean of the first 15 trials): young adults: $14.03 \pm 3.44 \mathrm{~s}$, older adults: $8.41 \pm 3.04 \mathrm{~s}$, group effect: $\mathrm{F}$ $(1,68)=52.4, p<0.001$ ] (Fig. 5c, d). Learning rate was significantly higher in the young participants [trial by age interaction: mean platform angle: $\mathrm{F}(14,660)=1.96$, $p=0.035$; mean balance time: $\mathrm{F}(14,663.06)=3.77, p<$ 0.001 ]. The trial effect was significant [trial effect: mean platform angle: $\mathrm{F}(14,660)=47.77, p<0.001$; mean balance time: $\mathrm{F}(14,663)=25.7, \mathrm{p}<0.001$ ]. In young participants (squares in Fig. $5 \mathrm{c}, \mathrm{d}$ ), the anodal group performed numerically below the sham group, but this

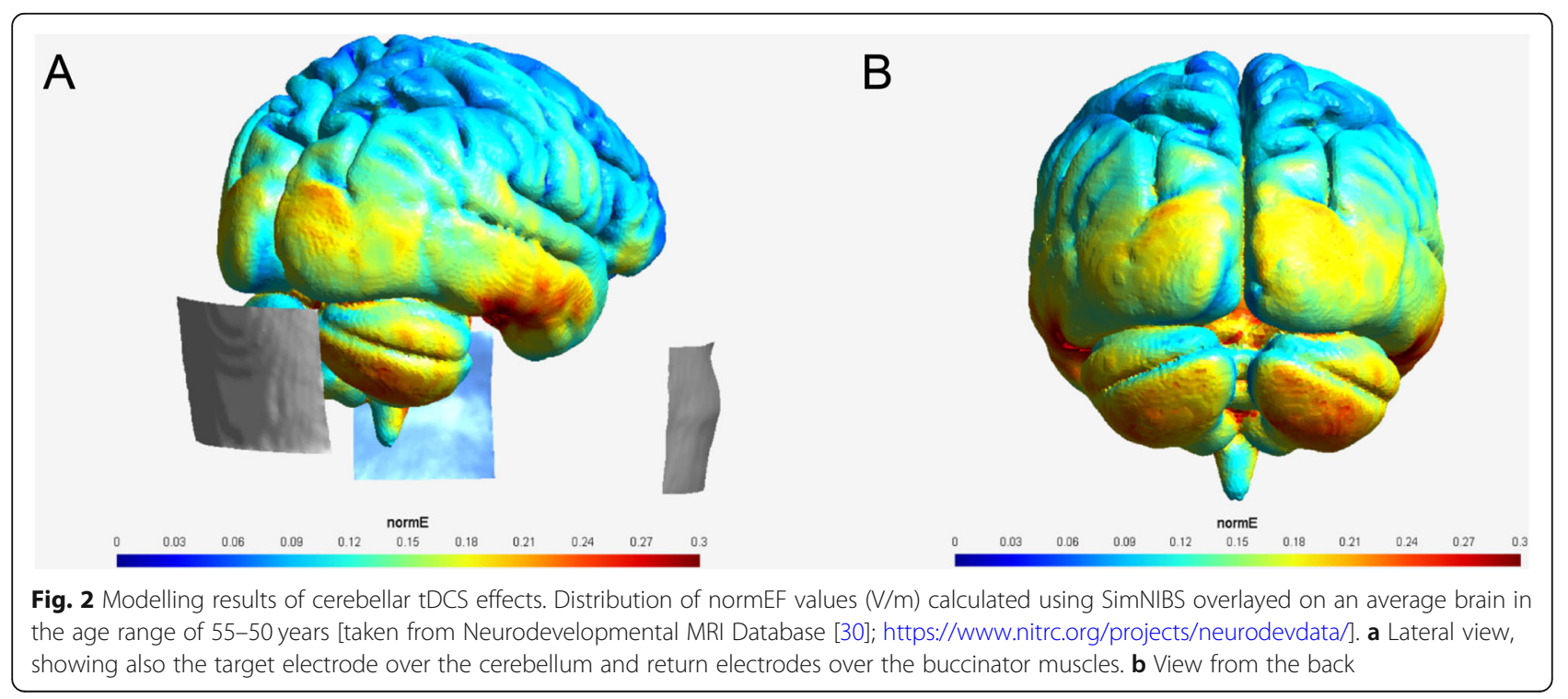




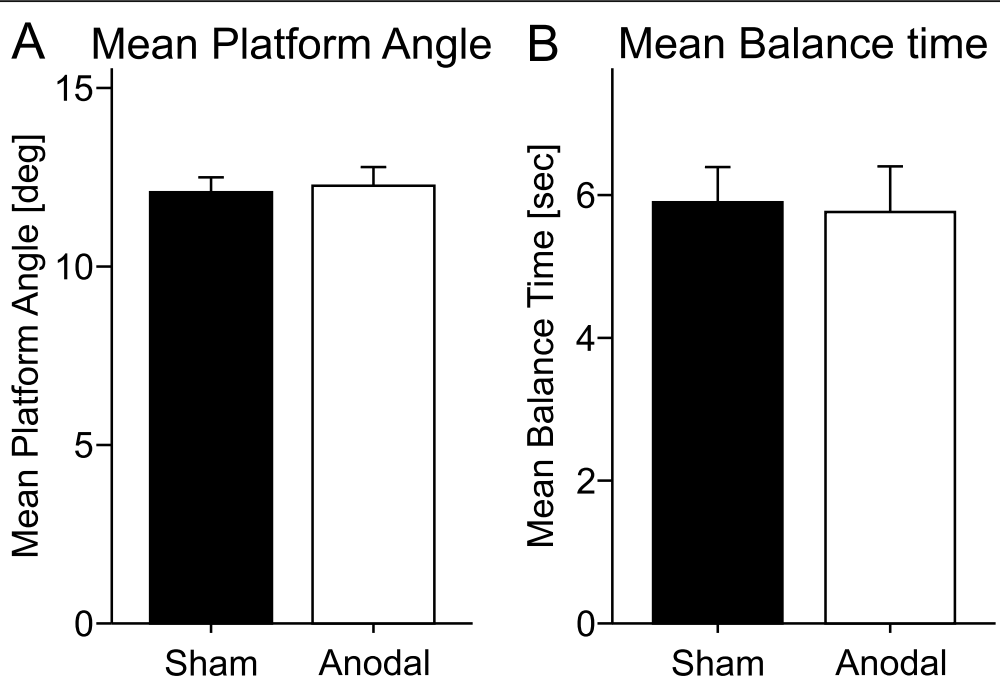

Fig. 3 Test trial with no stimulation applied. Mean platform angle and standard error of the mean, and mean balance time and standard error of the mean in the test trial in each stimulation group (verum vs. sham)

difference was not significant [mean platform angle: $\mathrm{F}$ $(1,18)=2.4, p=0.12$; mean balance time: $\mathrm{F}(1,18)=3.72$, $p=0.07]$.

\section{Discussion}

In the present study, anodal cerebellar tDCS had no effect on learning of a complex whole body dynamic balance task in healthy middle-aged adults. All participants were able to improve balancing over the twenty trials, measured by a significant increase in the mean balance time and a significant decrease in the mean platform angle, but without a significant difference between the stimulation and the sham group. The elderly participants performed significantly worse compared to the young healthy participants in our first study [36]. Thus, as expected, aging affected balancing capability and learning in this task. However, similar to our previous negative findings in young healthy participants, there was no significant effect of cerebellar tDCS in middle-aged adults. In young participants there was a trend that anodal stimulation impeded learning.

The present findings are in line with other studies on cerebellar tDCS showing no or inconsistent effects, not only with regard to balance function but also in other types of motor learning: Jalali et al. [18] conducted seven reach adaptation experiments varying task parameters in a large population of healthy young participants. No consistent cerebellar tDCS effects were obtained. Positive effects in one experiment could not be replicated in a second experiment using the same experimental set-
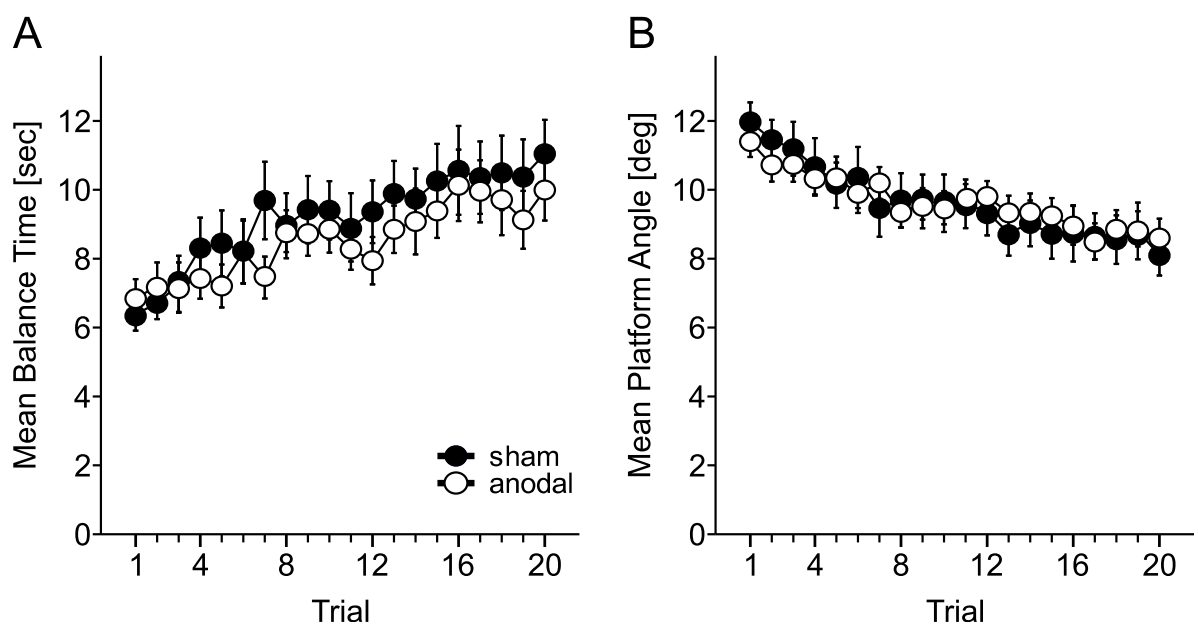

Fig. 4 Mean balance time and standard error of the mean (a), and mean platform angle and standard error of the mean (b) across the 20 learning trials. Black: sham group, white: anodal group 

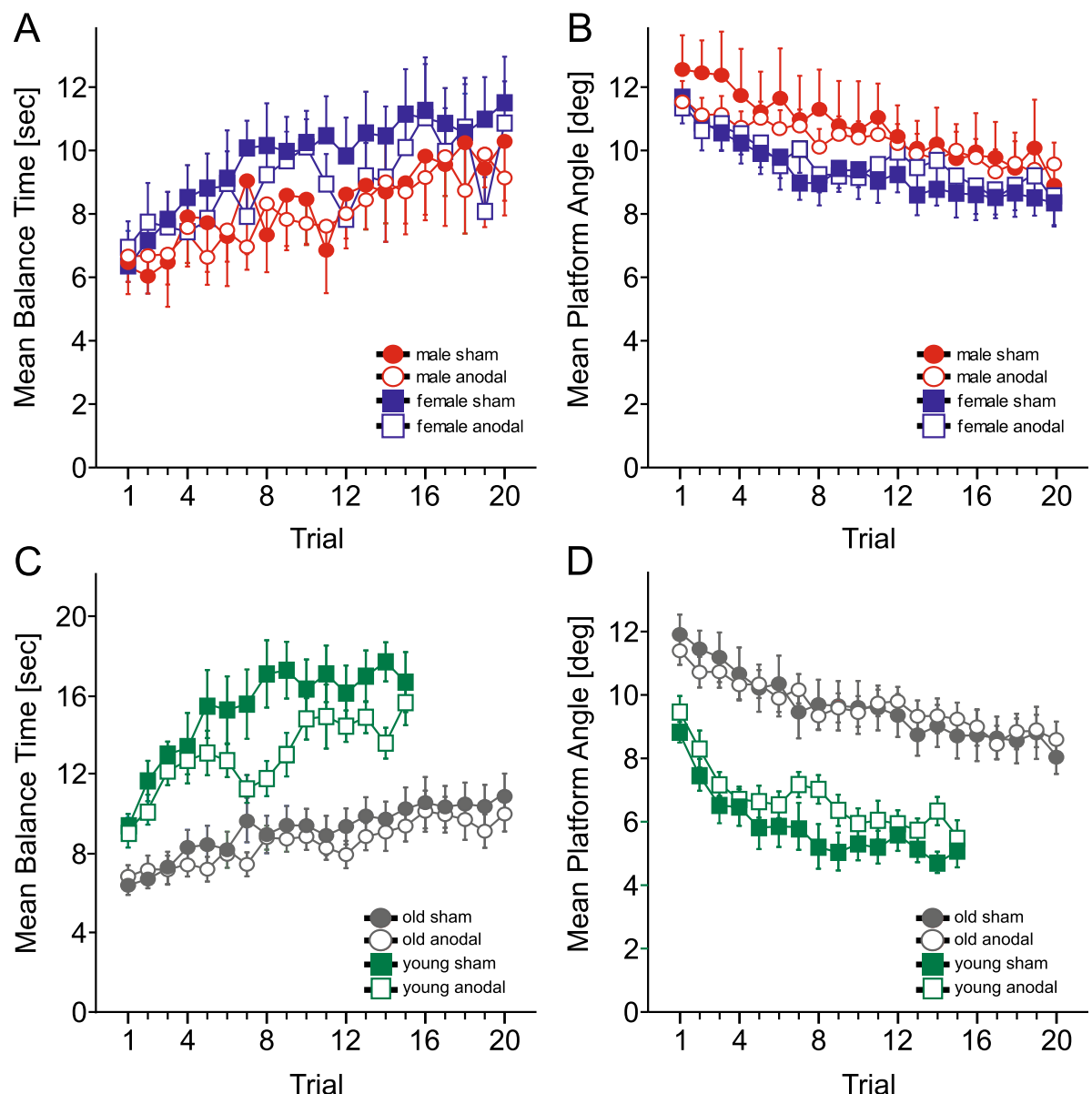

Fig. 5 Mean balance time and standard error of the mean $(\mathbf{a}, \mathbf{c})$ and mean platform angle and standard error of the mean $(\mathbf{b}, \mathbf{d})$ in each stimulation group, considering male and female participants separately $(\mathbf{a}, \mathbf{b})$ and comparing old and young participants in each stimulation group (c, d). Red circles: Male participants sham, white circles: male participants anodal, blue squares: female participants sham, white squares: female participants anodal. Grey circles: old participants sham, white circles: old participants anodal, green squares: young participants sham, white squares: young participants anodal

up, paradigm and stimulation parameters. Likewise, two studies of our group $[17,25]$ found no effect of cerebellar tDCS in a visuomotor reach adaptation task. Kaminski et al. [19] investigated the effect of tDCS in the same whole body dynamic balance task as in the present study but with different electrode positioning: the supplementary motor area was chosen as the stimulation target, as it is an area assumed to control multijoint whole body movements. Again, tDCS had no beneficial effect on balance learning [19].

Several reasons for the inconsistency of cerebellar tDCS effects have to be considered. Stimulation parameters such as current intensity, electrode placement and electrode size [28] might have been suboptimal with respect to either the stimulation target and/or task. One may argue that the tDCS montage did not sufficiently stimulate the cerebellar areas involved in the task. In fact, modelling of the electric field distribution suggests that cerebellar tDCS effects on the vermis and anterior cerebellar lobe were small. Cerebellar tDCS effects, however, were strong in Crus II bilaterally, but are also present in lobules VIII. Lobule VIII has been shown to be involved in the task by Taubert et al. [39]. The authors examined learning-related grey and white matter changes using the same dynamic balance task. Grey matter (GM) volume in the left lobule VIII correlated negatively with improvements in motor performance. Likewise, a GM decrease was found in lobule VIII bilaterally, and a mean diffusivity (MD) increase in right cerebellar white matter regions. Taubert and colleagues discussed "synaptic pruning, decreased synapse head-size due to long-term depression or proliferation of intracortical axons as possible mechanisms underlying grey matter reduction" [supplementary materials in [39]]. Because strategic learning plays a significant role in successfully performing the task $[6,39]$, we believe that Crus II likely plays a role because of its known connections with the prefrontal cortex $[10,38]$. Thus, although 
negative findings may be explained because tDCS effects on the vermis were minor, parts of the cerebellum, which are involved in the task, have been stimulated.

Furthermore tDCS effects may be more prominent in multiple session compared to single stimulation session studies [3]. There is also an ongoing discussion about individual differences in responsiveness to tDCS [21]. In addition, and may be most importantly, the highly convoluted structure of the cerebellar cortex makes it difficult to predict the overall tDCS effect which depends on current flow direction relative to the orientation of the axons [8], and may result in antagonistic effects dependent on the depth of penetration of the current [2]. Genetic polymorphisms might be another explanation for the conflicting results in cerebellar tDCS studies. The BDNF Val66Met polymorphism is thought to be associated with slowed motor skill learning due to altered long-term potentiation conditions [12, 26]. Van der Vliet and colleagues found susceptibility of noncarriers to anodal tDCS in eyeblink conditioning [43]. Finally, effect sizes of cerebellar tDCS may be much smaller than initially thought, and consistent tDCS effects may only be picked up in very large study populations [18].

In the present study, the performance of male participants appeared to be worse than the performance of female participants (Fig. 5). Similar to our previous study in young participants, this numerical difference was not significant [36]. We assume that significant differences in body height explain this gender difference. A significant correlation with height was found in a previous pilot study including participants with a height above $190 \mathrm{~cm}$ [37] (which were excluded in the present study).

\section{Conclusions}

In conclusion, we observed a lack of cerebellar tDCS effects on learning of a complex whole body dynamic balance task in middle-aged adults. Findings confirmed our previous negative findings in young healthy adults. However, further studies are needed before firm conclusions about cerebellar tDCS effects on motor learning tasks can be drawn.

\section{Abbreviations}

ANOVA: Analysis of variance; EF: Electric field; Fig: Figure; GM: Grey matter; ICARS: International Cooperative Ataxia Rating Scale; MD: Mean diffusivity; MRI: Magnetic Resonance Imaging; SARA: Scale for the Assessment and Rating of Ataxia; tDCS: Transcranial direct current stimulation; TOST: The Two One-Sided Test

\section{Acknowledgements}

Not applicable.

\section{Authors' contributions}

MR: subject recruitment and data acquisition. FY: analysis and interpretation. GB: analysis and interpretation. NL: analysis and interpretation. Wl: conception of the study, analysis and interpretation. MN: analysis and interpretation, critical revision of the manuscript. DT: conception of the study, analysis and interpretation, critical revision of the manuscript. KMS: conception of the study, analysis and interpretation, wrote the manuscript. The authors read and approved the final manuscript.

Funding

There was no funding.

Availability of data and materials

The datasets used and/or analysed during the current study are available from the corresponding author on reasonable request.

\section{Ethics approval and consent to participate}

The study was approved by the local ethics committee (Medical Faculty of the University Duisburg-Essen) and conducted in accordance with the Declaration of Helsinki. Oral and written informed consent was obtained from all subjects.

\section{Consent for publication}

I certify that all coauthors have seen the manuscript, agree with the contents and gave their written consent for publication.

\section{Competing interests}

All authors declare that there are no competing interests.

\section{Author details}

'Department of Neurology, Essen University Hospital, University of Duisburg-Essen, Hufelandstr. 55, 45147 Essen, Germany. ${ }^{2}$ Department of Psychology and Neurosciences, Leibniz Research Centre for Working Environment and Human Factors, Dortmund, Germany. ${ }^{3}$ Cognitive Neurology, Section Computational Sensomotorics, Hertie Institute for Clinical Brain Research and Center for Integrative Neuroscience, Eberhard Karls University, Tübingen, Germany. ${ }^{4}$ Department of Neurology, University Medical Hospital Bergmannsheil, Bochum, Germany.

Received: 24 May 2020 Accepted: 26 August 2020

Published online: 22 September 2020

\section{References}

1. Anguera, J. A., Reuter-Lorenz, P. A., Willingham, D. T., \& Seidler, R. D. (2011). Failure to engage spatial working memory contributes to age-related declines in visuomotor learning. Journal of Cognitive Neuroscience, 23(1), 11 25. https://doi.org/10.1162/jocn.2010.21451.

2. Batsikadze, G., Rezaee, Z., Chang, D. I., Gerwig, M., Herlitze, S., Dutta, A., ... Timmann, D. (2019). Effects of cerebellar transcranial direct current stimulation on cerebellar-brain inhibition in humans: A systematic evaluation. Brain Stimulation. https://doi.org/10.1016/j.brs.2019.04.010.

3. Benussi, A., Dell'Era, V., Cantoni, V., Bonetta, E., Grasso, R., Manenti, R., . Borroni, B. (2018). Cerebello-spinal tDCS in ataxia: A randomized, doubleblind, sham-controlled, crossover trial. Neurology, 91(12), e1090-e1101. https://doi.org/10.1212/WNL.0000000000006210.

4. Benussi, A., Koch, G., Cotelli, M., Padovani, A., \& Borroni, B. (2015). Cerebellar transcranial direct current stimulation in patients with ataxia: A doubleblind, randomized, sham-controlled study. Movement Disorders, 30(12), 1701-1705. https://doi.org/10.1002/mds.26356.

5. Bo, J., Peltier, S. J., Noll, D. C., \& Seidler, R. D. (2011). Age differences in symbolic representations of motor sequence learning. Neuroscience Letters, 504(1), 68-72. https://doi.org/10.1016/j.neulet.2011.08.060.

6. Caillou, N., Delignieres, D., Nourrit, D., Deschamps, T., \& Lauriot, B. (2002) Overcoming spontaneous patterns of coordination during the acquisition of a complex balancing task. Canadian Journal of Experimental Psychology, 56(4), 283-293. https://doi.org/10.1037/h0087404.

7. Cantarero, G., Spampinato, D., Reis, J., Ajagbe, L., Thompson, T., Kulkarni, K., \& Celnik, P. (2015). Cerebellar direct current stimulation enhances on-line motor skill acquisition through an effect on accuracy. The Journal of Neuroscience, 35(7), 3285-3290. https://doi.org/10.1523/JNEUROSCI.2885-14. 2015.

8. Chan, C. Y., \& Nicholson, C. (1986). Modulation by applied electric fields of Purkinje and stellate cell activity in the isolated turtle cerebellum. The Journal of Physiology, 371, 89-114. 
9. Diedrichsen, J. (2006). A spatially unbiased atlas template of the human cerebellum. Neuroimage, 33(1), 127-138. https://doi.org/10.1016/j. neuroimage.2006.05.056.

10. Dum, R. P., \& Strick, P. L. (2002). Motor areas in the frontal lobe of the primate. Physiology \& Behavior, 77(4-5), 677-682.

11. Ferrucci, R., Cortese, F. \& Priori, A. (2015). Cerebellar tDCS: How to do it. Cerebellum, 14(1), 27-30. https://doi.org/10.1007/s12311-014-0599-7.

12. Fritsch, B., Reis, J., Martinowich, K., Schambra, H. M., Ji, Y., Cohen, L. G., \& Lu, B. (2010). Direct current stimulation promotes BDNF-dependent synaptic plasticity: Potential implications for motor learning. Neuron, 66(2), 198-204. https://doi.org/10.1016/j.neuron.2010.03.035.

13. Galea, J. M., Jayaram, G., Ajagbe, L., \& Celnik, P. (2009). Modulation of cerebellar excitability by polarity-specific noninvasive direct current stimulation. The Journal of Neuroscience, 29(28), 9115-9122. https://doi.org/ 10.1523/JNEUROSCI.2184-09.2009

14. Galea, J. M., Vazquez, A., Pasricha, N., de Xivry, J. J., \& Celnik, P. (2011). Dissociating the roles of the cerebellum and motor cortex during adaptive learning: The motor cortex retains what the cerebellum learns. Cerebral Cortex, 21(8), 1761-1770. https://doi.org/10.1093/cercor/bha246.

15. Greenhouse, S. W., \& Geisser, S. (1959). On methods in the analysis of profile data. Psychometrika, 24(2), 95-112.

16. Hardwick, R. M., \& Celnik, P. A. (2014). Cerebellar direct current stimulation enhances motor learning in older adults. Neurobiology of Aging, 35(10), 2217-2221. https://doi.org/10.1016/j.neurobiolaging.2014.03.030.

17. Hulst, T., John, L., Küper, M., van der Geest, J. N., Göricke, S. L., Donchin, O., \& Timmann, D. (2017). Cerebellar patients do not benefit from cerebellar or M1 transcranial direct current stimulation during force field reaching adaptation. Journal of Neurophysiology, 118(2), jn 00808 02016. https://doi. org/10.1152/jn.00808.2016.

18. Jalali, R., Miall, R. C., \& Galea, J. M. (2017). No consistent effect of cerebellar transcranial direct current stimulation on visuomotor adaptation. Journal of Neurophysiology, 118(2), 655-665. https://doi.org/10.1152/jn.00896.2016.

19. Kaminski, E., Hoff, M., Sehm, B., Taubert, M., Conde, V., Steele, C. J., ... Ragert, P. (2013). Effect of transcranial direct current stimulation (tDCS) during complex whole body motor skill learning. Neuroscience Letters, 552, 76-80. https://doi.org/10.1016/..neulet.2013.07.034.

20. Küper, M., Mallick, J. S., Ernst, T., Kraff, O., Thürling, M., Stefanescu, M. R., ... Timmann, D. (2019). Cerebellar transcranial direct current stimulation modulates the fMRI signal in the cerebellar nuclei in a simple motor task. Brain Stimulation. https://doi.org/10.1016/j.brs.2019.04.002.

21. Labruna, L., Stark-Inbar, A., Breska, A., Dabit, M., Vanderschelden, B., Nitsche, M. A., \& Ivry, R. B. (2019). Individual differences in TMS sensitivity influence the efficacy of tDCS in facilitating sensorimotor adaptation. Brain Stimulation. https://doi.org/10.1016/j.brs.2019.03.008.

22. Lajoie, Y., Teasdale, N., Bard, C., \& Fleury, M. (1996). Upright standing and gait: Are there changes in attentional requirements related to normal aging? Experimental Aging Research, 22(2), 185-198. https:/doi.org/10.1080/ 03610739608254006

23. Laughton, C. A., Slavin, M., Katdare, K., Nolan, L., Bean, J. F., Kerrigan, D. C., .. Collins, J. J. (2003). Aging, muscle activity, and balance control: Physiologic changes associated with balance impairment. Gait \& Posture, 18(2), 101-108.

24. Macher, K., Bohringer, A., Villringer, A., \& Pleger, B. (2014). Cerebellar-parietal connections underpin phonological storage. The Journal of Neuroscience, 34(14), 5029-5037. https://doi.org/10.1523/JNEUROSCl.0106-14.2014.

25. Mamlins, A., Hulst, T., Donchin, O., Timmann, D., \& Claassen, J. (2019). No effects of cerebellar transcranial direct current stimulation on force field and visuomotor reach adaptation in young and healthy subjects. Journal of Neurophysiology, 121(6), 2112-2125. https://doi.org/10.1152/jn.00352.2018.

26. McHughen, S. A., Rodriguez, P. F., Kleim, J. A., Kleim, E. D., Marchal Crespo, L., Procaccio, V., \& Cramer, S. C. (2010). BDNF val66met polymorphism influences motor system function in the human brain. Cerebral Cortex, 20(5), 1254-1262. https://doi.org/10.1093/cercor/bhp189.

27. Poortvliet, P., Hsieh, B., Cresswell, A., Au, J., \& Meinzer, M. (2018). Cerebellar transcranial direct current stimulation improves adaptive postural control. Clinical Neurophysiology, 129(1), 33-41. https://doi.org/10.1016/j.clinph.2017. 09.118 .

28. Rampersad, S. M., Janssen, A. M., Lucka, F., Aydin, U., Lanfer, B., Lew, S., ... Oostendorp, T. F. (2014). Simulating transcranial direct current stimulation with a detailed anisotropic human head model. IEEE Transactions on Neural Systems and Rehabilitation Engineering, 22(3), 441-452. https://doi.org/10. 1109/TNSRE.2014.2308997.
29. Raz, N., Ghisletta, P., Rodrigue, K. M., Kennedy, K. M., \& Lindenberger, U. (2010). Trajectories of brain aging in middle-aged and older adults: Regional and individual differences. Neuroimage, 51(2), 501-511. https://doi.org/10. 1016/j.neuroimage.2010.03.020.

30. Richards, J. E., Sanchez, C., Phillips-Meek, M., \& Xie, W. (2016). A database of age-appropriate average MRI templates. Neuroimage, 124(Pt B), 1254-1259. https://doi.org/10.1016/j.neuroimage.2015.04.055.

31. Rogers, J. L., Howard, K. I., \& Vessey, J. T. (1993). Using significance tests to evaluate equivalence between two experimental groups. Psychological Bulletin, 113(3), 553-565.

32. Saturnino, G. B., Puonti, O., Nielsen, J. D., Antonenko, D., Madsen, K. H., \& Thielscher, A. (2019). SimNIBS 2.1: A comprehensive pipeline for individualized electric field Modelling for Transcranial brain stimulation. In S. Makarov, M. Horner, \& G. Noetscher (Eds.), Brain and human body modeling: Computational human modeling at EMBC 2018, (pp. 3-25). Cham.

33. Savic, B., \& Meier, B. (2016). How Transcranial direct current stimulation can modulate implicit motor sequence learning and consolidation: A brief review. Frontiers in Human Neuroscience, 10, 26. https://doi.org/10.3389/ fnhum.2016.00026.

34. Schmitz-Huebsch, T., du Montcel, S. T., Baliko, L., Berciano, J., Boesch, S., Depondt, C., ... Fancellu, R. (2006). Scale for the assessment and rating of ataxia: Development of a new clinical scale. Neurology, 66(11), 1717-1720. https://doi.org/10.1212/01.wnl.0000219042.60538.92.

35. Schuirmann, D. J. (1987). A comparison of the two one-sided tests procedure and the power approach for assessing the equivalence of average bioavailability. Journal of Pharmacokinetics and Biopharmaceutics, 15(6), 657-680.

36. Steiner, K. M., Enders, A., Thier, W., Batsikadze, G., Ludolph, N., Ilg, W., \& Timmann, D. (2016). Cerebellar tDCS does not improve learning in a complex whole body dynamic balance task in young healthy subjects. PLoS One, 11(9), e0163598. https://doi.org/10.1371/journal.pone.0163598.

37. Steiner, K. M., Thier, W., Batsikadze, G., Ludolph, N., Ilg, W., \& Timmann, D. (2020). Lack of effects of a single session of cerebellar transcranial direct current stimulation (tDCS) in a dynamic balance task. Journal of Neurology, 267(4), 1206-1208. https://doi.org/10.1007/s00415-020-09712-8.

38. Strick, P. L., Dum, R. P., \& Fiez, J. A. (2009). Cerebellum and nonmotor function. Annual Review of Neuroscience, 32, 413-434. https://doi.org/10. 1146/annurev.neuro.31.060407.125606.

39. Taubert, M., Draganski, B., Anwander, A., Muller, K., Horstmann, A., Villringer, A., \& Ragert, P. (2010). Dynamic properties of human brain structure: Learning-related changes in cortical areas and associated fiber connections. The Journal of Neuroscience, 30(35), 11670-11677. https://doi.org/10.1523/ JNEUROSCI.2567-10.2010.

40. Thielscher, A., Antunes, A., \& Saturnino, G. B. (2015). Field modeling for transcranial magnetic stimulation: A useful tool to understand the physiological effects of TMS? Conference Proceedings: Annual International Conference of the IEEE Engineering in Medicine and Biology Society, 2015, 222225. https://doi.org/10.1109/EMBC.2015.7318340.

41. Trouillas, P., Takayanagi, T., Hallett, M., Currier, R. D., Subramony, S. H., Wessel, K.,... Manyam, B. (1997). International cooperative ataxia rating scale for pharmacological assessment of the cerebellar syndrome. Journal of the Neurological Sciences, 145(2), 205-211. https://doi.org/10.1111/j.1365-2125. 2008.03158.x

42. Ugawa, Y., Uesaka, Y., Terao, Y., Hanajima, R., \& Kanazawa, I. (1995). Magnetic stimulation over the cerebellum in humans. Annals of Neurology, 37(6), 703713. https://doi.org/10.1002/ana.410370603.

43. van der Vliet, R., Jonker, Z. D., Louwen, S. C., Heuvelman, M., de Vreede, L., Ribbers, G. M., ... Frens, M. A. (2018). Cerebellar transcranial direct current stimulation interacts with BDNF Val66Met in motor learning. Brain Stimulation, 11(4), 759-771. https://doi.org/10.1016/j.brs.2018.04.009.

44. Xu-Wilson, M., Chen-Harris, H., Zee, D. S., \& Shadmehr, R. (2009). Cerebellar contributions to adaptive control of saccades in humans. The Journal of Neuroscience, 29(41), 12930-12939. https://doi.org/10.1523/JNEUROSCI.311509.2009 .

\section{Publisher's Note}

Springer Nature remains neutral with regard to jurisdictional claims in published maps and institutional affiliations. 